\title{
ENTRE A INVESTIGAÇÃO-AÇÃO, A SUPERVISÃO E A REFLEXÃO NA FORMAÇÃO INICIAL DE EDUCADORES DE INFÂNCIA NO PORTUGAL DE HOJE
}

\author{
Amélia Marchão ${ }^{1}$, Helder Henriques ${ }^{2}$ \\ ${ }^{1}$ Doutora em Ciências da Educação com Pós-doutoramento em Educação. Coordenadora do Departamento de \\ Educação e Formação e docente da Escola Superior de Educação e Ciências Sociais do Instituto Politécnico de \\ Portalegre. Investigadora do VALORIZA - Research Center for Endogenous Resource Valorization (Portugal) \\ ${ }^{2}$ Doutor em Ciências da Educação com Pós-doutoramento em Ciências da Educação e Pósdoutoramento em Educação. \\ Docente da Escola Superior de Educação e Ciências Sociais do Instituto Politécnico de Portalegre e Investigador do \\ GRUPOEDE Ceis20 Universidade de Coimbra (Portugal).
}

\section{RESUMO}

Este artigo pretende discutir a formação inicial de educadores de infância sob a vigência da legislação mais atual em Portugal. Pretende, sobretudo, focar-se nos processos de estágio e no modo como os mesmos se desenrolam questionando a investigação-ação como modelo e as práticas de supervisão numa perspetiva de questionamento crítico. Os autores partem da sua experiência e reflexão enquanto formadores e supervisores da formação inicial numa Instituição de Ensino Superior em Portugal e conjugam no seu exercício reflexivo uma revisão da bibliografia especializada, que inclui resultados de estudos que desenvolveram e cujo principal objetivo foi escutar as vozes das estudantes sobre os processos de estágio, seja em creche ou seja nos jardins de infância que atendem as crianças até ao seu ingresso na escolaridade obrigatória. Apontam, a partir da revisão da literatura, das suas experiências e revisitação às vozes das estudantes envolvidas em dois estudos, as principais tendências observadas: a importância dos canais de comunicação entre a instituição de formação e os locais de estágio; a importância e os aspetos a ter em conta durante o estágio/investigação-ação e a importância de uma supervisão que agilize o pensamento crítico das estagiárias.

Palavras-chave: Formação inicial, educadores de infância, estágios, investigação-ação, supervisão, reflexão.

\section{BETWEEN RESEARCH ACTION, SUPERVISION AND REFLECTION IN THE INITIAL TRAINING OF CHILDREN EDUCATORS TODAY}

\section{ABSTRACT}

This article aims to discuss the initial training of children educators under the current legislation in Portugal. Above all, it intends to focus on internship processes and how they unfold by questioning research action as a model and supervisory practices from a critical questioning perspective. The authors build on their experience and reflection as trainers and supervisors of initial training in a Higher Education Institution in Portugal and combine in their reflective exercise a review of the specialized bibliography, which includes results of studies they developed and whose main objective was to listen to the voices of students about internship processes, whether in day care or kindergartens that serve children until they enter school. From the literature review, their experiences and revisiting the voices of the students involved in two studies, they point out the main trends observed: the importance of communication channels between the training institution and the internship places; the importance and aspects to be taken into account during the internship / research action and the importance of a supervision that streamlines the critical thinking of trainees.

Keywords: initial education, early childhood educators, internships, research action, supervision, reflection

\section{ENTRE LA INVESTIGACIÓN ACCIÓN, LA SUPERVISIÓN Y LA REFLEXIÓN EN LA FORMACIÓN INICIAL DE} EDUCADORES DE LA INFANCIA EN PORTUGAL HOY 


\section{RESUMEN}

Este artículo pretende discutir la formación inicial de educadores infantiles bajo la vigencia de la legislación más actual en Portugal. Pretende, sobre todo, centrarse en los procesos de prácticas y en la forma como éstos se desarrollan cuestionando la investigación-acción como modelo, las prácticas de supervisión en una perspectiva de cuestionamiento crítico y las representaciones de las estudiantes sobre esos mismos procesos. Los autores parten de su experiencia y reflexión como formadores y supervisores de la formación inicial en una institución de educación superior en Portugal y conjugan en su ejercicio reflexivo una revisión de la bibliografía especializada, que incluye los resultados de los estudios que desarrollaron y cuyo principal objetivo ha sido escuchar las voces de estudiantes sobre los procesos de prácticas, ya sea en guarderías o en los jardines de infancia que cuidan a niños hasta su ingreso a la escuela obligatoria. Apuntan, a partir de la revisión de la bibliografía, de sus experiencias y de las voces de las estudiantes participantes en dos estudios, las principales tendencias observadas: la importancia de los canales de comunicación entre la institución de formación y los locales de prácticas; la importancia y los aspectos a tener en cuenta durante la práctica/investigación-acción y la importancia de una supervisión que agilice el pensamiento crítico de las alumnas en prácticas.

Palabras clave: Formación inicial, educadores infantiles, prácticas, investigación-acción, supervisión, reflexión.

\section{INTRODUÇÃO}

Em Portugal, a formação de educadores de infância (adiante designados de educadores) faz-se sob a regência de um conjunto de diplomas legais, dos quais destacamos o Decreto-Lei n.으 79/2014, que estipula o regime jurídico da habilitação profissional para a docência na educação pré-escolar e nos ensinos básico e secundário (PORTUGAL, 2014). Este regime estipula que a formação dos educadores é de nível superior e adquirida com o grau de Mestre em Educação Pré-escolar ${ }^{1}$ ou em Educação Préescolar e Ensino do 1.o Ciclo do Ensino Básico, sequente a uma Licenciatura em Educação Básica.

A Licenciatura que antecede o grau de Mestre é organizada em 180 créditos $^{2}$ que se distribuem por quatro componentes específicas. A saber: Área da docência com um mínimo de 125 créditos, distribuídos pela Matemática (30 créditos), pelo Português (30 créditos), pelas Ciências Naturais e História e Geografia de Portugal (30 créditos) e Expressões (30 créditos); Área Educacional Geral com um mínimo de 15 créditos; Didáticas Específicas com um mínimo de

\footnotetext{
${ }^{1}$ Que habilita para a docência na educação de infância (creche, jardim de infância).

${ }^{2}$ ECTS - Sistema Europeu de Transferência de Créditos. No quadro do Acordo de Bolonha, que assenta na possibilidade de um estudante de uma determinada instituição e país poder ver o trabalho realizado durante o seu percurso de formação traduzido de uma forma numérica, inequívoca, legível e transferível no espaço europeu de ensino superior (https://www.ipportalegre.pt/static/sites/guia/sobre_ects.htm).
}

15 créditos; e Iniciação à Prática Profissional com um mínimo de 15 créditos.

O Mestrado em Educação Pré-escolar organiza-se em 90 créditos, distribuídos por quatro componentes - Área da Docência com um mínimo de 6 créditos; Área Educacional Geral com um mínimo de 6 créditos; Didáticas Específicas com um mínimo de 24 créditos; e Prática de Ensino Supervisonada com um mínimo de 39 créditos. O Mestrado em Educação Préescolar e Ensino do 1. Ciclo do Ensino Básico organiza-se em 120 créditos que integram: Área da Docência com o mínimo de 18 créditos; Área Educacional Geral com o mínimo de 6 créditos; Didáticas Específicas com um mínimo de 36 créditos; e Prática de Ensino Supervisionada com o mínimo de 48 créditos.

$$
\text { O mesmo Decreto-Lei no 79/2014 }
$$
(PORTUGAL, 2014) estipula que os ciclos de estudos que habilitam profissionalmente para a docência devem organizar-se tendo como referenciais os princípios estabelecidos na Lei de Bases do Sistema Educativo Português - Lei n.o 46/86 (PORTUGAL, 1986), as orientações gerais de política educativa e, no caso de habilitarem para o exercício profissional na educação de infância, as Orientações Curriculares para a Educação Pré-escolar vigentes em Portugal.

No contexto deste artigo iremos situar a nossa discussão e reflexão no quadro do Mestrado em Educação Pré-escolar, em termos gerais e, de modo particular na componente de Prática de Ensino Supervisionada. Teremos como base a interface entre a revisão da literatura no 
campo da formação de educadores e de professores, a nossa experiência docente na formação de educadores, em particular enquanto supervisores da Prática de Ensino Supervisionada, e a revisitação a dois estudos que se centraram nas "vozes" dos alumni de um Mestrado em Educação Pré-escolar realizado numa Instituição de Ensino Superior Politécnico em Portugal.

Assim, a partir de um mapeamento bibliográfico os autores realizaram a respetiva revisão da literatura que, segundo Cardoso, Alarcão e Celorico (2010), é não só um ponto de partida de qualquer trajeto de investigação, mas também um ponto de chegada que permite uma compreensão mais forte e coerente da temática em investigação, permitindo a edificação do estado da arte sobre essa mesma temática. Integrou-se na seleção bibliográfica a revisitação ao corpus de conhecimento desenvolvido a partir dos dois estudos desenvolvidos pelos autores ${ }^{3}$. 0 primeiro estudo revisitado centrou-se na supervisão enquanto estratégia de formação e o segundo centrou-se na investigação-ação enquanto estratégia de estágio e promotora do desenvolvimento profissional.

A revisitação aos dados desses estudos, através de uma matriz crítica e reflexiva associada à revisão da bibliografia e à experiência dos autores do presente artigo nos processos formativos de futuros educadores, possibilitou a discussão que se plasma seguidamente.

\section{A formação de educadores de infância - abordagem teórica a partir de uma revisão do estado da arte}

Assume-se que num mundo em constante evolução a formação de educadores e de professores é constantemente questionada no sentido da sua qualidade e da sua adaptação às constantes exigências que se colocam à profissão docente, sendo que o exercício docente é hoje envolto em múltiplos desafios e complexidades que requerem, do ponto de vista formativo, exigências extremas no sentido de facilitar aos

\footnotetext{
3 Primeiro estudo: Representações dos estudantes sobre os processos de supervisão, estudo realizado pelos autores do presente artigo com alumni do Mestrado em Educação Pré-escolar do Instituto Politécnico de Portalegre, no ano de 2016. Segundo estudo: Representações dos estudantes sobre os contributos da investigação-ação, usada enquanto modelo de estágio, para a construção da identidade profissional; este estudo foi realizado com alumni do Mestrado em Educação Pré-escolar do Instituto Politécnico de Portalegre e foi realizado em 2018; para além dos autores deste artigo envolveu mais dois docentes do mesmo Instituto Politécnico.
}

futuros profissionais competências ${ }^{4}$ científicas, pedagógicas e de índole pessoal referidas à autonomia, à criatividade e ao pensamento crítico, entre outras. A formação dos educadores para esse mundo cheio de múltiplos desafios deve, pois, realizar-se num quadro socio construtivista, ecológico e de matriz reflexiva e crítica, fazendo emergir o sentido questionador e investigativo do futuro profissional que favoreça o sentido humanista da profissão docente e a indagação e reflexão-crítica, como meios para fazer melhor e elevar a qualidade dos processos de ensinar e de aprender.

Como referem Mesquita, Roldão e Machado (2019) alguém que se torna educador/professor completou com sucesso a formação incial e construiu conhecimentos e competências que são necessárias para o exercício da docência. Desses conhecimentos destacam-se os saberes científicos sobre o que se ensina, os saberes psicopedagógicos em diferentes áreas das ciências da educação, os saberes pedagógicos e contextuais específicos dos locais onde se realiza a formação prática (estágios) e que incluem o funcionamento das instituições educativas, as interações com outros profissionais e crianças, o exercício da ética profissional e o exercício da reflexão e da investigação articuladas na interface teoria e prática.

Neste decurso, a componente de formação prática durante a formação inicial é um dos eixos estruturantes de todo o ciclo formativo, a par das componentes científico-didáticas e do rigor dos ambientes formativos que propiciam a emergência do questionamento, da investigação sobre a profissão, do pensamento crítico e reflexivo do sujeito em formação, promovendo o seu ser e o seu estar. Os educadores precisam de aprender a lidar com crianças muito diversas e provenientes de diferentes ambientes sociais e culturais, distintas no seu ser, no seu estar e nas suas competências para interagir com o mundo e com o conhecimento e precisam, como salienta Flores (2003), de construir e demonstrar conhecimento pedagógico e didático "[...] fundamentado para selecionar e construir melhores materiais e estratégias curriculares no

\footnotetext{
${ }^{4}$ Entendemos por competência a agilização ou mobilização do conhecimento em resposta a um problema num dado contexto, ou seja, o modo como o educador "[...] utiliza o seu conhecimento, nas suas diferentes dimensões e o integra nas suas capacidades para resolver os variados problemas do contexto educativo-pedagógico de forma mais adequada [...]" (MARCHÃO, 2012, p. 94).
} 
contexto da sala de aula que se caracteriza por uma heterogeneidade e uma complexidade cada vez maiores" (FLORES, 2003, p. 129).

$\mathrm{Na}$ articulação entre a teoria e a prática o futuro educador constrói-se para a profissão através de processos de transformação do eu e de construção do conhecimento profissional, o que inclui os conhecimentos científicos e técnicos e os conhecimentos práticos. Estes últimos crescem com a "[...] experiência e pela mobilização do pensamento crítico e reflexivo sobre os problemas do quotidiano" (MARCHÃO; HENRIQUES, 2019, p. 77), com as relações interpessoais e com a complexidade, a volubilidade, a singularidade e o conflito de valores que caracterizam o practicum (MARCHÃO; HENRIQUES, 2019).

A primeira revelação das competências construídas durante a formação inicial ocorre nos contextos de prática onde se desenvolvem os estágios ${ }^{5}$ e deve mostrar um agir profissional que demonstre pertinência, mobilização e transferência de saberes e conhecimentos de modo responsivo ao contexto, integração e articulação da multiplicidade de saberes construídos, empenhamento, compromisso, capacidade para aprender a aprender, ética e pensamento inteligente ${ }^{6}$ e reflexivo. Tornar-se educador é, pois, um processo longo e de grande comprometimento da pessoa em formação (mas também da pessoa-formador) que se inicia durante a formação inicial. É um comprometimento com o contexto de estágio, associando a investigação-ação e o exercício do pensamento crítico e reflexivo que contribuem para a formação intelectual, mas também para a autonomia, para a maior responsabilidade e trabalho em equipa, fundadas na conjugação entre o olhar a profissão como educadorinvestigador e como pensador inteligente.

Acresce, como dizem Mesquita e Machado (2019, p. 43), que a aprendizagem da docência não é um processo fácil, pois a "[...] realidade da docência é uma prática que gera linguagens contraditórias, porque está sujeita a muitas forças de influência externas e internas", pelo que, em nosso entender, as instituições de formação são constantemente desafiadas a criarem ambientes formativos que estimulem os futuros educadores a gerar e demonstrar sentido

\footnotetext{
${ }^{5}$ No caso português estes incluem a Prática e Ensino Supervisionada e acontecem ao longo dos Mestrados.

${ }^{6}$ Pensamento inteligente ou pensamento crítico utilizados como sinónimos, à luz dos constructos de Marchão (2012).
}

crítico, abertura à inovação, competências reflexivas e disponibilidade para investigar a docência.

Esse desafio institucional é transversal a todas as componentes da formação, mas somos a considerar e a destacar a componente de Prática e Ensino Supervisionada como o eixo estruturante da formação "em concomitância com componentes científico-didáticas sustentadas na teoria, no rigor do practicum e com um ambiente de supervisão coerente e a concorrer para o exercício do pensamento crítico e reflexivo" (MARCHÃO; HENRIQUES, 2019, p. 74) dos candidatos a educador.

Nesse contexto, associada ao estágio, surge a supervisão, mas também a investigaçãoação, enquanto estratégias para despertar o pendor investigativo na/da prática, assinalando que os processos supervisivos devem mobilizar o pensamento inteligente, crítico e reflexivo focado na pessoa e nos contextos onde, no caso, se desenrolam os estágios, e que a investigaçãoação propicia o planeamento para a ação, a própria ação e a reflexão focada nos contextos e alicerçada no conhecimento da/sobre a prática “[...] através da organização rigorosa e persistência na análise de dados que vão emergindo e de uma competência reflexivacrítica em ascensão [...]" (MARCHÃO et al., 2018, p. 76).

$\mathrm{Na}$ nossa experiência formativa associamos, ao longo dos estágios, um processo supervisivo a um trajeto de investigação-ação, o que nem sempre se afigura fácil e sempre constitui um desafio em que não nos podemos desfocar da pessoa em formação, deixando-lhe espaço para ser e aprender a profissão docente em crescente responsabilização e autonomia. Ao mesmo tempo, encaramos essa associação como naturalmente em devir, dado que a formação é sempre um processo transformativo.

$\mathrm{Em}$ tal associação consideramos a supervisão totalmente necessária ${ }^{7}$ e entendemola enquanto processo e tempo de interações que deve privilegiar "[...] estratégias de agilização do pensamento crítico, contribuindo para a construção dos conhecimentos e das competências profissionais num ambiente autonómico e reflexivo, mas também espaço e tempo coletivo favorecedor de uma identidade

\footnotetext{
${ }^{7} \mathrm{E}$ também exigida no enquadramento legal da formação inicial de educadores e professores - Decreto-Lei n. 79/2014.
} 
profissional [...]" (MARCHÃO; HENRIQUES, 2019, p. 83-84).

Esta imprescindibilidade da supervisão justifica-se em termos legais, mas sobretudo porque a supervisão é hoje entendida como uma cultura de aprendizagem indispensável e focada na emergência de um pendor reflexivo-crítico e investigador que caracteriza os bons profissionais, sendo que, como salientam Alarcão e Tavares (2003), a supervisão enquanto processo intra e interpessoal visa a melhoria da qualidade nas escolas. Enquanto cultura de aprendizagem a supervisão gera conhecimentos e provoca a transformação de atitudes e a mobilização de conhecimentos na esfera e especificidades da profissão docente.

No quadro da formação inicial, ela é um processo e simultaneamente uma estratégia para ensinar a ensinar, que integra uma dimensão de orientação e que se promove através de uma tríade (estudante-cooperante-supervisor) ${ }^{8}$. Como referido por Marchão et al. (2018, p. 82) a supervisão é estruturante e concorre para a "[...] valorização da pessoa-estudante, das suas ideias, acentuando a sua autonomia e competência".

Não sendo a supervisão um processo somente técnico, ele é simultaneamente social com dimensões cognitivas e relacionais, suportado pela colocação de andaimes (VASCONCELOS, 2009) e pela intervenção formativa de um supervisor com capacidade para observar e interpretar, que tenha conhecimentos sobre os contextos e conteúdos científicos e pedagógicos sobre os quais exerce a supervisão, que valorize a dimensão interpessoal e com pensamento crítico e inteligência interpessoal.

O tempo e o espaço da supervisão, quando associados à investigação-ação, devem evoluir para o questionamento e para a problematização do contexto e das ações dos candidatos a educadores e, naturalmente devem estar alicerçados na confluência entre a teoria e a prática e em competências reflexivas que irão permitir clarificar o que se faz, como se faz e como se pode (re)fazer em ações sequentes. Nesse sentido, problematizar, questionar e refletir, usando o pensamento inteligente enquanto atribuidor de significados, implementase através da supervisão e da investigação-ação,

\footnotetext{
${ }^{8} \mathrm{Na}$ Instituição de Ensino Superior em que os autores do artigo exercem, os processos supervisivos incluem: os estudantes candidatos a educador, o supervisor (docente da Instituição de Ensino Superior) e o educador cooperante, também designado de orientador.
}

que consiste na "exploração reflexiva que o professor [educador] faz da sua prática, contribuindo dessa forma não só para a resolução de problemas como também (e principalmente!) para a planificação e introdução de alterações nessa mesma prática" (COUTINHO, 2015, p. 364).

É, desse modo, que se contribui para que o estagiário integre na sua ação a centralidade da criança, uma boa dinâmica curricular, o trabalho colaborativo, o trabalho com as famílias (entre outros pontos fundamentais da sua ação), assumindo em emergência a construção de uma dada identidade profissional, através da conjugação de conhecimentos, atitudes e competências específicas da profissão docente. Como dizem Mesquita, Formosinho e Machado (2012, p. 66) os futuros educadores começam assim a construir a sua profissionalidade, "[...] estimulando o seu desempenho também através de uma forma reflexiva e exercendo, deste modo, uma influência indireta na aprendizagem das crianças e melhoria dos contextos, e consequentemente, na qualidade da educação".

Durante o estágio, a prática da investigação-ação permite o planeamento, a ação e a reflexão centrada nos contextos (creches e jardins de infância), elevando o grau de responsividade dos candidatos a educador às situações, fenómenos e exigências educativas e pedagógicas nesses mesmos contextos. Entre a supervisão e a investigação-ação, o candidato a educador vai desenvolvendo a sua competência crítica e reflexiva e vai compreendendo a ação educativo-pedagógica através do questionamento e da investigação do que faz, como faz e como poderá fazer, tornando-se um educador disponível para a problematização do conhecimento específico na sua área de intervenção e no seu desempenho e desenvolvimento profissional.

Assim, no quadro da formação inicial, que representações têm os candidatos a educador sobre os processos supervisivos e sobre a investigação-ação, enquanto processos/estratégias formativas? É ao que nos propomos responder através da interface entre dois estudos realizados e que mobilizamos neste artigo para expressar a voz de um conjunto dos alumni, candidatos a educadores.

\section{A formação de educadores de infância - uma abordagem a partir da revisitação de dados empíricos}


Da revisitação aos estudos desenvolvidos salienta-se que tais estudos foram realizados sobre a égide da investigação qualitativa, na metodologia de caso, com destaque matricial do tipo interpretativo-reflexivo.

O primeiro, Representações dos estudantes sobre os processos de supervisão, centrado na recolha das "vozes" de alumni do Mestrado em Educação Pré-escolar, objetivou perceber e interpretar a sua perceção sobre os processos de supervisão desenvolvidos e sobre a importância que lhes atribuíram no processo formativo. Este envolveu uma amostra aleatória constituída por vinte e cinco estudantes ( $54 \%$ de diplomados) que frequentaram o Mestrado entre 2010 e 2015. A taxa de retorno foi de $100 \%$. O segundo, Representações dos estudantes sobre os contributos da investigação-ação, usada enquanto modelo de estágio, para a construção da identidade profissional, objetivou perceber as representações acerca da importância da investigação-ação enquanto estratégia formativa no estágio e facilitadora da construção do desenvolvimento profissional. Neste caso o questionário foi enviado a 30 alumni que concluíram o Mestrado entre 2013 e 2018, sendo a taxa de retorno de 53,3 (16 respostas).

As vozes dos alumni (no caso, do sexo feminino) foram recolhidas através de questionários construídos em cada um dos estudos e ambos disponibilizados online através dos Formulários do Google. No primeiro estudo foi construído um questionário com questões abertas e fechadas, agrupadas em dois blocos ( 1 Identificação; II - Perceções sobre os processos de supervisão vivenciados). O questionário do segundo estudo, igualmente construído por questões abertas e fechadas estruturou-se em três blocos (I - Identificação pessoal; II Identificação profissional; III - Formação inicial). Quer num caso quer no outro, algumas das questões fechadas foram respondidas através de escalas valorativas do tipo Likert.

Nos dois casos, os dados recolhidos foram sujeitos a processos de análise através do programa Excel (respostas fechadas) e a procedimentos de análise de conteúdo (respostas abertas), identificando, após uma leitura e uma análise cuidada das respostas, categorias e/ou subcategorias.

Assim, no primeiro estudo, Representações dos estudantes sobre os processos de supervisão, os alumni tinham idades compreendidas entre os 22 e os 32 anos e, na sua maioria, à data de resposta ao questionário, estavam a exercer a profissão de educadora de infância ou já a tinham exercido.

As participantes foram questionadas sobre a importância da supervisão durante os estágios na sua formação inicial. As suas respostas foram assinaladas através de uma escala em que 1 significava nada importante e 5 muito importante. As suas respostas centraramse no nível 5 da escala (24 participantes) e no nível 4 ( 1 participante), o que nos permite destacar que a supervisão é vista e percecionada como uma estratégia/processo formativo que ganha, na voz dos alumni, destaque na formação inicial.

No seguimento do questionário colocouse uma questão relacionada com os perfis dos supervisores que as acompanharam durante a formação inicial - supervisores generalistas e supervisores especialistas, sendo que os do tipo generalista correspondem aos supervisores cuja formação inicial é a educação pré-escolar e os do tipo especialistas são supervisores com formação inicial em áreas disciplinares específicas (Matemática, Língua Portuguesa, Expressões e Conhecimento do Mundo/Ciências, História, Geografia). Usando de novo uma escala (1 nada importante e 5 muito importante) tentou apurarse como é que as participantes valoraram a participação dos dois tipos de supervisores na orientação e supervisão dos seus estágios. As respostas distribuíram-se conforme a Tabela seguinte.

Tabela 1. Valoração dos/as supervisores/as de acordo com o seu perfil

\begin{tabular}{|ccccc}
\hline $\begin{array}{c}\text { Escala Valorativa e } \\
\text { número de } \\
\text { registos/respostas }\end{array}$ \\
\hline $\mathbf{1}$ & $\mathbf{2}$ & $\mathbf{3}$ & $\mathbf{4}$ & $\mathbf{5}$ \\
\hline 4 & 0 & 7 & 4 & 8 \\
\hline 4 & 0 & 5 & 2 & 14 \\
\hline 4 & 0 & 5 & 3 & 13 \\
\hline 4 & 0 & 6 & 4 & 12 \\
\hline
\end{tabular}

\begin{tabular}{llllll}
\hline $\begin{array}{l}\text { Generalista/Formação em } \\
\text { educação de infância }\end{array}$ & 0 & 0 & 0 & 3 & 22
\end{tabular}

Legenda: Adaptado de Marchão e Henriques, 2016. (Org.: Autores, 2019)

Como se verifica, a participação dos supervisores do tipo generalista é mais valorada do que a dos supervisores do tipo especialista. Os primeiros são valorados ao nível 5 (muito 
importante) e ao nível 4 (importante), sendo que os do tipo especialistas são valorados de modo mais distribuído entre o nível 1 (nada importante), pelo nível 3 (nem muito nem pouco importante), pelo nível 4 e pelo nível 5 . Na nossa análise às respostas dadas destaca-se que o sentido dessas respostas pode advir do facto de os supervisores do tipo generalista estarem focados na profissão de educador de infância e de, no processo de supervisão, conseguirem evidenciar mais a sua proximidade com as especificidades da educação pré-escolar, nomeadamente na centralidade da criança em todo a ação educativa e na identificação de um modo de desenvolver a pedagogia da infância mais consentânea com práticas menos escolarizadas e próprias das dinâmicas curriculares em participação e de um currículo não previamente estabelecido, mas em construção partilhada (educador-criançasfamílias-comunidade). Também por demonstrarem um conhecimento mais próximo dos contextos educativos (creches e jardins de infância), gerador de uma comunicação menos formal e mais genuína com os locais de estágio, e um conhecimento prático da pedagogia da infância que os supervisores do tipo generalista poderão ter mais apurado do que os supervisores do tipo especialista.

Em associação a esta questão, as participantes foram desafiadas a identificar as competências do supervisor que consideraram mais importantes. Foi-lhes apresentada uma lista de 13 competências e a hierarquia das competências surge do seguinte modo:

Tabela 2. Competências do/a supervisor/a consideradas mais importantes

\begin{tabular}{lc}
\hline \multicolumn{1}{c}{ Competências dos supervisores } & $\begin{array}{c}\text { Números de } \\
\text { registos/respostas }\end{array}$ \\
\hline Ter competências práticas & 9 \\
\hline $\begin{array}{l}\text { Saber orientar as estudantes sobre os processos em } \\
\text { educação de infância }\end{array}$ & 5 \\
\hline Deixar as estudantes serem criativas & 4 \\
\hline Conhecer bem as creches e os jardins de infância & 4 \\
\hline Promover a confiança nas estudantes & 2 \\
\hline Estabelecer boas relações interpessoais com & 1 \\
estudantes & 0 \\
\hline Ter competências teóricas & 0 \\
\hline Ser autoritário com as estudantes & 0 \\
\hline Ser exigente com as estudantes & 0 \\
\hline Criar stress nas estudantes & 0 \\
\hline Ser controlador & 0 \\
\hline Ser experiente & 0 \\
\hline Ser diretivo & \\
\hline
\end{tabular}

Legenda: Adaptado de Marchão e Henriques, 2016. (Org.: Autores, 2019)

Como se verifica, são valorizadas competências que apontam para o saber e conhecimento do supervisor sobre os contextos e sobre a profissão de educador e que se situam na esfera das relações pessoais e interpessoais e, a este propósito, relembramos as palavras de Alarcão e Tavares (2003) quando dizem que a supervisão é um processo intra e interpessoal, que deverá considerar o educador enquanto pessoa, que esse educador se encontra numa situação de aprendizagem e que o supervisor é também uma pessoa em desenvolvimento cuja missão é ajudar o educador a aprender e a desenvolver-se.

Para além desta listagem de competências associadas ao supervisor, foi apresentado um outro conjunto de competências a valorar numa escala de 1 a 3 , em que 1 corresponde a menos importante e 3 a mais importante. A Tabela seguinte elenca as respostas das participantes. 
Tabela 3. Outras competências do/a supervisor/a

\begin{tabular}{llccc} 
& $\begin{array}{c}\text { Escala valorativa e } \\
\text { número de } \\
\text { registos/respostas }\end{array}$ \\
\hline $\begin{array}{l}\text { O supervisor é alguém com quem as estudantes... } \\
\text { se sentem à vontade }\end{array}$ & $\mathbf{1}$ & $\mathbf{2}$ \\
\hline $\begin{array}{l}\text { não se inibem para discutir os problemas e as } \\
\text { questões do estágio }\end{array}$ & 0 & 0 & 23 \\
\hline $\begin{array}{l}\text { podem questionar e refletir sobre as atividades } \\
\text { desenvolvidas }\end{array}$ & 0 & 0 & 25 \\
\hline constroem confiança e autoconfiança & 0 & 1 & 24 \\
\hline
\end{tabular}

Legenda: Adaptado de Marchão e Henriques, 2016. (Org.: Autores, 2019)

As respostas apontam para um processo de supervisão que deve desenvolver-se num clima aberto, marcado pelas boas relações pessoais e interpessoais, baseadas na confiança e favorecedoras do protagonismo do sujeito em formação, que vá ganhando confiança e autonomia no trajeto transformativo para a profissão através da elicitação do questionamento e da reflexão. As respostas das participantes alicerçam-se na ideia de que a supervisão deve promover a pessoa em devir no seu desenvolvimento pessoal-profissional através de uma crescente confiança dos sujeitos na ação que desenvolvem, de uma crescente confiança no relacionamento entre os sujeitos das díades (estagiária-supervisor) ou tríades (estagiáriaeducador cooperante/orientador-supervisor) e no reconhecimento das competências do supervisor. Como referem Mesquita e Roldão (2019), apoiadas em Bolton (2014), “[...] considera-se a supervisão como um direito, uma atividade de desenvolvimento pessoal e profissional [...]" (p. 19).

Em questões de resposta aberta, as participantes confirmaram a importância da supervisão, enquanto estratégia que promove a confiança, a orientação, o apoio e a reflexão para um processo transformativo e ético em crescente autonomia e de crescente envolvimento na profissão. Igualmente consideraram a indispensabilidade da supervisão na formação inicial, pelo facto da construção partilhada do conhecimento profissional e do saber fazer em equipa, não estando sozinho no trajeto e percurso formativo. Concomitantemente destacaram, em unanimidade, a importância de a supervisão promover canais de comunicação positivos entre os contextos (instituição de ensino superior-creche e jardim de infância) e os sujeitos envolvidos (estagiário-educador cooperante/orientador-supervisor).

A supervisão deve, assim,
certificar que o
relacionamento entre os
sujeitos envolvidos seja
orientado de forma
idónea, pautada por
padrões éticos,
disposições legais e por
uma práxis profissional de
qualidade, no sentido de
promover e proteger o
bem-estar da pessoa em
formação, da profissão, e
da sociedade em geral
(MESQUITA; ROLDÃO,
2019, p. 19).

Porém, nessas respostas do tipo aberto também consideraram que os supervisores do tipo especialista deverão estar mais "por dentro" das realidades educativas (creche e jardim de infância) com maior conhecimento sobre as crianças dos zero aos seis anos, das pedagogias que lhes são mais adequadas e que não apontam para a escolarização precoce da criança. Reconhecem igualmente o equilíbrio que o supervisor do tipo generalista impõe na comunicação com os locais de estágio, nos momentos de planeamento, de agir e de refletir sobre a ação educativo-pedagógica, dado o seu maior conhecimento sobre as crianças da faixa etária mencionada, de um maior conhecimento da pedagogia da educação de infância e do conhecimento organizacional dos próprios contextos de estágio, bem como da maior 
facilidade com que interage com as educadores cooperantes/orientadores.

No segundo estudo, Representações dos estudantes sobre os contributos da investigaçãoação, usada enquanto modelo de estágio, para a construção da identidade profissional, os alumni apresentavam idades que variavam entre os $22 \mathrm{e}$ os 30 anos. Na sua maioria, à data da resposta ao questionário, já exerciam ou estavam a exercer a profissão de educadora de infância.

No bloco do questionário que apontava para identificar a importância da investigação- ação enquanto estratégia formativa, utilizada no estágio em associação com os processos de supervisão, os alumni foram convidados a responder a uma questão aberta. Consideraram, em unanimidade, a importância da investigaçãoação vivenciada no estágio e consideraram, de uma lista de 15 hipóteses justificativas, as cinco que consideraram como os mais relevantes contributos da investigação-ação. A saber e em hierarquia, apresenta-se as respostas na Tabela seguinte.

Tabela 4. Contributos da investigação assinalados pelas participantes

\section{Contributos mais relevantes da investigação-ação}

Conhecer melhor o grupo de crianças e assim planear e desenvolver a ação, tendo em atenção as suas necessidades

Processo participativo e colaborativo

Ajudou a perspetivar a necessidade de refletir para a ação e de refletir sobre a ação

Construir conhecimento acerca da prática que fui desenvolvendo

Compreender a ação educativa através do questionamento e da investigação de novas formas de agir

\begin{tabular}{ll}
\hline $\begin{array}{l}\text { Conhecer melhor a instituição e estar atenta aos seus } \\
\text { problemas/especificidades }\end{array}$ & 6 \\
\hline Processo de constante questionamento & 6 \\
\hline $\begin{array}{l}\text { Desenvolve-se num ciclo (planear com flexibilidade, agir, refletir, avaliar, } \\
\text { validar, dialogar) que ajuda a construir um sentido profissional forte }\end{array}$ & 6 \\
\hline Compreender melhor a ação educativa e a melhorá-la & 5 \\
\hline $\begin{array}{l}\text { Constante questionamento e de problematização da prática que me ajudou na } \\
\text { construção de uma identidade profissional }\end{array}$ & 3 \\
\hline Processo em que fui protagonista da ação e da investigação realizada & 3 \\
\hline Um maior conhecimento do contexto & 2 \\
\hline Incorporar nos saberes pedagógicos a ação da criança & 2 \\
\hline Organizar e analisar dados de modo mais rigoroso e sistematizado & 1 \\
\hline Estabelecer um diálogo entre a teoria e a prática & 1 \\
\hline
\end{tabular}
Legenda: Adaptado de Marchão, et al., 2018. (Org.: Autores, 2019)

A investigação-ação foi apontada como facilitadora do conhecimento dos contextos/locais de estágio e dos sujeitos aí incluídos. Tal conhecimento é indispensável para a organização e desenvolvimento de uma ação educativo-pedagógica que tenha a criança como figura central e que se funde na reflexão e numa ação participativa e colaborativa. Latorre (2003) destaca que a investigação-ação permite mais conhecimento sobre os contextos e sujeitos, que se constrói, interpreta e compreende a partir da observação associada ao questionamento da prática e dos valores que Ihe são inerentes. Como é referido por Marchão e Henriques (2019), o compromisso da supervisão associado à investigação-ação

[...] funda-se na necessidade de questionar e problematizar o contexto e as ações vividas pelos futuros educadores/professores, numa exploração reflexiva da ação e confluência teoria-prática, resultado da promoção do pensamento crítico dos 
sujeitos que enriquecesse

a reflexão dos educadores/professores e que importa agilizar na formação inicial, pois é garantia da construção de uma identidade profissional dialogante, crítica e reflexiva (MARCHÃO; HENRIQUES, p. 84).
A partir das mesmas hipóteses, questionaram-se os alumni sobre o que, no desenvolvimento do estágio através da investigação-ação, tinha sido mais difícil e também mais fácil. A Tabela seguinte sistematiza as respostas dadas, sendo que cada participante apenas podia indicar as cinco mais difíceis e as cinco mais fáceis.

Tabela 5. O mais difícil e o mais fácil de concretizar na investigação-ação

\begin{tabular}{|c|c|c|}
\hline A investigação-ação no contexto do estágio & $\begin{array}{l}\text { O que foi mais } \\
\text { difícil } \\
\text { (número de } \\
\text { registos/respostas) }\end{array}$ & $\begin{array}{l}\text { O que foi mais fácil } \\
\text { (número de } \\
\text { registos/respostas) }\end{array}$ \\
\hline $\begin{array}{l}\text { Conhecer melhor o grupo de crianças e assim } \\
\text { planear e desenvolver a ação, tendo em atenção as } \\
\text { suas necessidades }\end{array}$ & 3 & 10 \\
\hline Processo participativo e colaborativo & 1 & 8 \\
\hline $\begin{array}{l}\text { Ajudou a perspetivar a necessidade de refletir para } \\
\text { a ação e de refletir sobre a ação }\end{array}$ & 10 & 5 \\
\hline $\begin{array}{l}\text { Construir conhecimento acerca da prática que fui } \\
\text { desenvolvendo }\end{array}$ & 3 & 9 \\
\hline $\begin{array}{l}\text { Compreender a ação educativa através do } \\
\text { questionamento e da investigação de novas formas } \\
\text { de agir }\end{array}$ & 4 & 9 \\
\hline $\begin{array}{l}\text { Conhecer melhor a instituição e estar atenta aos } \\
\text { seus problemas/especificidades }\end{array}$ & 5 & 11 \\
\hline Processo de constante questionamento & 7 & 6 \\
\hline $\begin{array}{l}\text { Desenvolve-se num ciclo (planear com } \\
\text { flexibilidade, agir, refletir, avaliar, validar, dialogar) } \\
\text { que ajuda a construir um sentido profissional forte }\end{array}$ & 9 & 3 \\
\hline $\begin{array}{l}\text { Compreender melhor a ação educativa e a } \\
\text { melhorá-la }\end{array}$ & 3 & 4 \\
\hline $\begin{array}{l}\text { Constante questionamento e de problematização } \\
\text { da prática que me ajudou na construção de uma } \\
\text { identidade profissional }\end{array}$ & 6 & 2 \\
\hline $\begin{array}{l}\text { Processo em que fui protagonista da ação e da } \\
\text { investigação realizada }\end{array}$ & 4 & 3 \\
\hline Um maior conhecimento do contexto & 7 & 1 \\
\hline $\begin{array}{l}\text { Incorporar nos saberes pedagógicos a ação da } \\
\text { criança }\end{array}$ & 6 & 4 \\
\hline $\begin{array}{l}\text { Organizar e analisar dados de modo mais rigoroso } \\
\text { e sistematizado }\end{array}$ & 7 & 2 \\
\hline Estabelecer um diálogo entre a teoria e a prática & 6 & 3 \\
\hline
\end{tabular}

Legenda: Adaptado de Marchão, et al., 2018. (Org.: Autores, 2019)

As cinco hipóteses assinaladas como representando maior dificuldade no contexto da investigação-ação situaram-se nas questões da reflexão para e sobre a ação, no ciclo do planeamento, na organização rigorosa e sistematizada de dados e no maior conhecimento do contexto. As cinco hipóteses assinaladas como representando maior facilidade situaram-se em questões como: o conhecimento da instituição e do grupo para agir em maior consentaneidade, a 
construção do conhecimento acerca da prática e a maior compreensão da ação educativa por via do questionamento e da investigação.

As respostas dos alumni confirmaram a importância da investigação-ação no seu trajeto formativo no estágio. Manifestaram o envolvimento de cada uma na situação de estágio, contudo, destacaram a dificuldade dos processos de questionamento e de reflexão incluídos na investigação-ação. Esta atividade pensante pode ser cada vez mais elaborada se o supervisor e o educador cooperante/orientador forem atuando no apelo ao pensamento crítico dos estagiários, através de uma linguagem que "ajude a clarificar as ideias, que ajude a persistir no pensamento para a reflexão, na ação e sobre a ação e que ajude a sistematizar o conhecimento e a precisar competências de ordem pessoal e profissional" (MARCHÃO; HENRIQUES, 2019, p. 88). Como ainda refere Máximo-Esteves (2008, p. 42) a reflexão e o sentido crítico da investigaçãoação é indispensável para aumentar a "[...] sabedoria prática [...]" que se alicerça na colaboração entre os sujeitos envolvidos e em canais de comunicação positivos, transparentes e éticos.

A investigação-ação foi igualmente apontada como a facilitadora de um sentir-se verdadeiramente educador ao longo do estágio. Setenta e cinco por cento dos alumni subscreveu essa ideia e alguns justificaram a sua resposta através de categorias como as que constam da Tabela seguinte.

Tabela 6. Contributos da investigação-ação para o sentir-se verdadeira educadora durante o estágio

\begin{tabular}{lc}
\multicolumn{1}{c}{ Categorias identificadas } & $\begin{array}{c}\text { Número de } \\
\text { registos/respostas }\end{array}$ \\
\cline { 2 - 2 } & 2 \\
\hline $\begin{array}{l}\text { Permite questionamento e reflexão } \\
\text { Os adultos }\end{array}$ & 2 \\
\hline Permite responder melhor às necessidades das crianças & 2 \\
\hline É um suporte de desenvolvimento profissional & 1 \\
\hline A IA permite agir e investigar & 3 \\
\hline É importante & 7 \\
\hline
\end{tabular}

Legenda: Adaptado de Marchão, et al., 2018. (Org.: Autores, 2019)

Como se percebe, os alumni continuaram a destacar no seu trajeto de estágio em investigação-ação aspetos como o questionamento e a reflexão, o envolvimento e as interações, o agir e o investigar. Aportando nas palavras de Máximo-Esteves (2008) traduz-se a ideia de que a investigação-ação ajuda o profissional a desenvolver competências enquanto educador-investigador e assim compreende melhor o contexto onde age, podendo desse modo melhorar a qualidade das respostas educativas. No entanto, esse é um percurso individual, mas vivido em díade ou tríade supervisiva que potencia a aprendizagem e o tornar-se educador/a.

\section{CONCLUSÕES}

A revisão do estado da arte e a revisitação a dois estudos antes desenvolvidos pelos autores deste artigo de revisão reforçam a ideia de que a formação inicial de educadores de infância é complexa e requer forte investimento das Instituições de Ensino Superior que formam tais profissionais. Igualmente reforçam a ideia da necessidade de uma forte articulação entre os diferentes componentes de formação e permitem destacar a prática pedagógica (estágio) como eixo estruturante.

Concomitantemente permitem perceber, na atualidade, uma tendência para que os estágios se desenvolvam num quadro de investigação-ação associado a uma supervisão centrada na pessoa em formação e nos contextos reais de educação das crianças dos zero aos seis anos (creche e jardim de infância). Através das vozes dos alumini percebemos a importância que tal associação tem na formação inicial de educadores, sobretudo porque tais vozes apontaram para competências construídas num perfil de docente reflexivo e investigador da sua prática. 
A indispensabilidade da supervisão é claramente afirmada, quer na revisão da literatura quer na revisitação das vozes dos alumni, bem como são destacadas as potencialidades da investigação-ação, apesar de sobre esta serem apontadas dificuldades relativas a aspetos fundamentais da formação. Como exemplo destas dificuldades, as vozes dos alumni apontam o exercício da reflexão, embora reconhecendo que ele é necessário no processo formativo. Como sabemos, o processo supervisivo é determinante para apoiar os futuros profissionais a apurarem o seu pensamento inteligente e cabe ao supervisor usar estratégias que promovam a reflexão como uma competência pensante que integra o perfil dos bons profissionais.

Percebe-se que, no quadro da investigação-ação e da supervisão vivenciada pelos alumni, estes interagiram com supervisores do tipo generalista e do tipo especialista bem como educadores cooperantes/orientadores. Sobre os supervisores, os alumni percecionaram uma aproximação mais genuína dos primeiros (do tipo generalista) aos contextos e práticas educativas próprias da pedagogia da infância, reconhecendo que estes também promoviam uma comunicação de maior proximidade (porque menos formal) com os contextos e os sujeitos envolvidos nos estágios.

Os desafios que vão emergindo nos estágios colocam os futuros profissionais à prova e o tornar-se educador, num quadro de investigação-ação, desperta-os para a problematização e investigação da realidade e do agir profissional. Tal facto é identificado na literatura em revisão e percecionado na revisitação às vozes dos alumni. Também se perceciona que o caminho se faz no individual, mas também no coletivo, no quadro das tríades e de uma supervisão ecológica e crítica que assuma a relação da teoria-prática-teoria e que faça emergir o eu do estagiário, a sua autonomia e a sua criatividade para projetar a ação educativopedagógica. A investigação-ação e a supervisão parecem concorrer para um devir profissional centrado na pessoa e nas suas competências para um exercício profissional alicerçado no coletivo, na autonomia, na investigação e na reflexão para responder aos problemas e desafios do quotidiano.

Assume-se que a investigação-ação é exigente, mas facilitadora de mais e melhor conhecimento e que ajuda a providenciar uma resposta educativo-pedagógica mais responsiva e baseada nas necessidades e nos interesses das crianças, bem como mais construída em colaboração. A investigação-ação é um compromisso coletivo e colaborativo; a supervisão permite que esse compromisso se vá fortalecendo, à medida que se desenvolve a confiança entre estudantes/estagiários e os supervisores, incluindo também a relação com os educadores cooperantes/orientadores. Estar à vontade, não se sentir inibido para discutir problemas e questões, poder questionar e refletir sobre o que se fez e para fazer melhor e construir confiança e autoconfiança foram condições apontadas pelos alumni que são necessárias e fundamentais nestes contextos formativos. Nesse sentido, aponta-se para que a investigação-ação e a supervisão associada se realizem numa perspetiva colaborativa, mas reflexiva-crítica, e fundadora de uma ação emancipatória dos sujeitos em formação.

Em conclusão, assume-se a centralidade da prática realizada nos estágios como eixo estruturante da formação e, por isso, ela deve ser devidamente pensada e também questionada, "[...] enquanto dinâmica [em] espiral e cíclica, interativa e aberta, focada na realidade dos contextos de estágio e conciliando um constante questionamento e atitude crítica [...]" (MARCHÃO; HENRIQUES, 2019, 85) que favoreça a aprendizagem da prática e que facilite a emancipação da voz do futuro educador de infância.

\section{REFERÊNCIAS}

ALARCÃO, I.; TAVARES, J. Supervisão da prática pedagógica. Uma perspectiva de desenvolvimento e aprendizagem 2 . ed. Coimbra: Almedina, 2003.

CARDOSO, T.; ALARCÃO, I.; CELORICO, J. Revisão da literatura e sistematização do conhecimento. Porto: Porto Editora, 2010.

COUTINHO, C. P. Metodologia de investigação em Ciências Sociais e Humanas: teoria e prática. Coimbra: Almedina, 2015.

FLORES, M. A. Dilemas e desafios na formação de professores. In: MORAIS, M. C.; PACHECO, J. A.; EVANGELISTA, M. O. (Orgs), Formação de professores: perspectivas educacionais e curriculares. Porto: Porto Editora, 2003. p. 127160. 
LATORRE, A. La investigación-acción. Barcelo: Graó, 2003.

MARCHÃO, A. No jardim de infância e na escola do 1. - ciclo do ensino básico - gerir o currículo e criar oportunidades para construir o pensamento crítico. Lisboa: Edições Colibri, 2012.

MARCHÃO, A.; HENRIQUES, H. Perceções das estudantes: processos de supervisão desenvolvidos na prática de ensino supervisionada. In: MESQUITA, C.; PIRES, M. V.; LOPES, R. (Edit.), Livro de atas. 1. Encontro Internacional de Formação na Docência (INCTE). Bragança: Instituto Politécnico de Bragança, 2016. p. 577-587.

MARCHÃO, A.; HENRIQUES, H. Formação inicial de educadores e de professores, supervisão e pensamento crítico. In: MESQUITA, E.; ROLDÃO, M. C.; MACHADO, J. (Org.), Prática supervisionada e construção do conhecimento profissional. Vila Nova de Gaia: Fundação Manuel Leão, 2019. p. 73-92.

MARCHÃO, A., REBOLA, F., HENRIQUES, H., \& CARVALHO, L. A Prática de Ensino Supervisionada, a investigação-ação e a construção da identidade profissional. In: POMAR, C.; COSTA, C.; BEZELGA I.; MOREIRA, L.; MAGALHÃES, O. (Coords.), A Formação de Educador@s e Professor@s: olhares a partir da UniverCidade de Évora. Évora: Centro de Investigação em Educação e Psicologia da Universidade de Évora, 2018. p. 76-103. Disponível em https://www.ciep.uevora.pt/Publicacoes/publica coes_nao_periodicas/Ebook-FEPUE. Acesso em 25 out. 2019.

MÁXIMO-ESTEVES, L. Visão panorâmica da investigação-acção. Porto: Porto Editora, 2008.

MESQUITA, E.; ROLDÃO, M. C. A supervisão como dispositivo de desenvolviemnto profissional e transformação de práticas. In: MESQUITA, E.; ROLDÃO, M. C.; MACHADO, J. (Org.), Prática supervisionada e construção do conhecimento profissional. Vila Nova de Gaia: Fundação Manuel Leão, 2019. p. 13-40.

MESQUITA, E.; FORMOSINHO, J.; MACHADO, J. Supervisão da prática pedagógica e colegialidade docente. A perspetiva dos candidatos a professores. Revista Portuguesa de Investigação Educacional, Braga-PT, v. 12, p. 57-75, 2012.

MESQUITA, E.; ROLDÃO, M. C.; MACHADO, J. (2019). Introdução. In: MESQUITA, E.; ROLDÃO, M. C.; MACHADO, J. (Org.), Prática supervisionada e construção do conhecimento profissional. Vila Nova de Gaia: Fundação Manuel Leão, 2019. p. 7-11.

PORTUGAL. Lei n. 46/86 de 14 de outubro. Lei de Bases do Sistema Educativo Português. Ministério Público: Procuradoria-Geral Distrital de Lisboa, 1986.

PORTUGAL. Decreto-Lei no 79/2014, de 14 de maio. Regime jurídico da habilitação profissional para a docência na educação pré-escolar e nos ensinos básico e secundário. Diário da República Eletrônico, Portugal. 2014. 